\title{
Thermomechanical and Isothermal Fatigue Behavior of Gray Cast Iron for Automotive Brake Discs
}

\author{
Omar Maluf, Jéferson Aparecido Moreto, Maurício Angeloni, \\ Marco Antônio Colósio, José Carlos Santos, \\ Waldek Wladimir Bose Filho and Dirceu Spinelli. \\ Department of Materials, Aeronautic and Automotive Engineering, University of São Paulo \\ Brazil
}

\section{Introduction}

At the end of the 19th century, in the wake of railway transportation and the beginning of automotive vehicle production, new technology-based materials became necessary for the manufacture of brake systems to provide safer and more effective braking of vehicles transporting heavy loads at higher speeds. These devices serve to decelerate vehicles by friction, transforming most of the kinetic energy into thermal energy, which is dissipated by the brake system during the braking process [IOMBRILLER, 2002].

Many parts contribute actively or passively to a vehicle's satisfactory performance, but safety is closely linked to the efficiency of the brake system, which is subjected to relatively high thermal and mechanical stresses during regular braking action. Therefore, a crucial factor is the precision of the analysis and development of brake systems taking into account all the aspects involved in their thermal and dynamic behavior [MAZUR et al., 2005].

During severe deceleration by braking, the temperature of the brake system may reach up to $650^{\circ} \mathrm{C}$ and overheating of the brake discs may lead to serious consequences that reduce the vehicle's safety [IOMBRILLER, 2002]. This temperature variation causes thermal shock and localized overheating points, changing the behavior of the metal involved due to metallurgical transformations, as well as crack nucleation in the disc in response to plastic flow of the surface metal and inducing stresses after cooling [MAZUR et al., 2005].

Even disregarding the presence of thermal shock, a few braking cycles with abrupt deceleration still suffice to produce small cracks in the usable part of brake discs. The study of the mechanical behavior and fracture mechanisms of these materials is essential to allow for the design and rational use of these components. Figure 1 illustrates the failure in front brake rotor in a disc submitted to penetrating liquid inspection to reveal cracks.

The cyclic stresses resulting from the continuous use of vehicles can cause fatigue, propagate cracks and fracture of the brake component [IOMBRILLER, 2002]. This mechanism may cause crack nucleation and growth in the material when subjected to cyclic strain. As cyclic loading conditions in brake discs are induced mainly by temperature gradients, thus essentially strain-controlled tests were planned for this study. In this way, it 


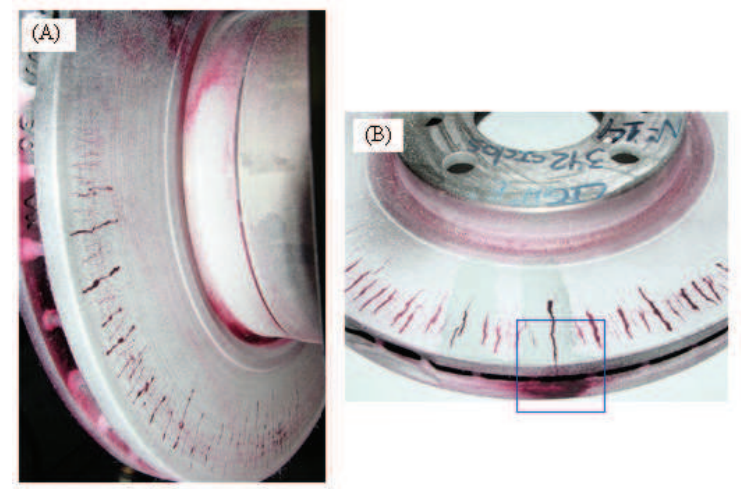

Fig. 1. (A) After 160 cycles, and (B) after 320 cycles. Note the macroscopic cracks propagating on the friction surface along the radial direction, extending from the inner to the outer radius of the disc [Maluf, 2007].

is clear that cracking in brake discs should be seen as an isothermal and thermomechanical problem. Isothermal Fatigue (IF) consists in the application of a variable mechanical strain at a constant temperature. The main advantages of this test are its simplicity and lower cost than that of anisothermal tests (thermomechanical).

Until recently, the fatigue strength of materials at high temperatures was estimated based on IF tests at the maximum temperature expected in the Thermal Fatigue (TF) cycle. However, this procedure proved to be insufficient because the strength of materials in TMF is significantly lower than that expected for the IF-based estimate. This is due to mechanisms possibly activated during the thermal cycling of TMF, which does not occur in IF, where the temperature is kept constant.

There are two main types of brake systems: drum and disc. The use of disc in place of drum brakes in heavy vehicles has become increasingly common in recent years.

This is due mainly to the search for greater braking efficiency, since disc brakes withstand higher temperatures than drum brakes [BOIOCCHI, 1999]. However, simply changing the drum shoe for the disc pad system does not suffice, making it necessary to analyze the brake system as a whole, as well as its influence on the vehicle's performance and safety.

In many high responsibility applications - as in the case of brake discs, knowing the results of tensile, impact and hardness testing is not enough to characterize the materials used in components, because these results cannot provide the information needed to reliably predict the behavior of these parts in real working conditions. Ideally, the materials used in brake systems should possess several properties such as good thermal conductivity, good corrosion resistance, good durability, stable friction, low wear rate and good cost-benefit [WEINTRAUB, 1998].

\subsection{Thermomechanical Fatigue - TMF}

Several components are subject to a variety of thermomechanical and isothermal loading due to temperature variations during a vehicle's operation. The cyclic loading conditions induced by temperature gradients are essentially loads limited by strain. Therefore, laboratory studies of Isothermal Fatigue, IF, are usually limited by strain control in low cycle fatigue tests [HETNARSKI, 1991]. 
Thermomechanical fatigue, TMF, describes fatigue under simultaneous variation of temperature and mechanical strain. Mechanical strain, which is determined by subtracting the thermal strain from the total strain, should be uniform in every specimen and originates from external restrictions or loads applied externally, e.g., if a specimen is held between two rigid walls and subjected to thermal cycling (without allowing expansion), it will undergo external compressive mechanical strain. Examples of TMF can be found in pressure vessels and pipes in the electric power industry, where structures undergo pressure loads and thermal transients with temperature gradients in the thickness direction, and in the aeronautical industry, where turbine blades and discs undergo temperature gradients superimposed to rotation-related stresses.

According to Sehitoglu [SEHITOGLU, 1996] TMF may involve several mechanisms in addition to fatigue damage, including creep at high temperatures and oxidation, which contribute directly to damage. These mechanisms differ depending on the history of strain and temperature. They are different from those foreseen by the phenomenon of creep tests (non-reverse) and by oxidation tests in the absence of stresses (or of constant stresses).

Microstructural degradation may occur under TMF in the form of:

1. Overaging, such as the coalescence of precipitates and formation of lamellae;

2. Strain aging, in the case of solid solution hardening systems;

3. Precipitation of secondary phase particles; and

4. Phase transformation within the cycle's ultimate temperature.

Variations in the mechanical properties or in the coefficient of thermal expansion in the matrix and precipitates, which are present in many alloys, also result in local stresses and cracks. These mechanisms influence the material's strain characteristics, which are associated with damage processes.

\subsection{Isothermal Fatigue - IF}

IF test consists of imposing variable mechanical strains while maintaining the temperature constant. This type of test has been widely employed since the 1970s, with the advent of test machines operating in closed cycle. The main advantages of this test are its simplicity and low cost when compared to anisothermal tests, and results for a variety of materials are available in the literature [COFFIN Jr, 1954].

Observations by researchers have shown that service life under IF is longer than that found in anisothermal fatigue [HETNARSKI, 1951; SHI et al., 1998]. This was reported by Shi et al. [SHI et al., 1998] in a study of a molybdenum alloy containing $0.5 \%$ of $\mathrm{Ti}, 0.08 \%$ of $\mathrm{Zr}$ and C in the range of 0.01 to $0.04 \%$, see Figure 2 .

The lifes obtained in IF tests at two temperature levels studied, $350^{\circ} \mathrm{C}$ and $500^{\circ} \mathrm{C}$, were higher, in both cases, than those found in TMF in phase for temperatures from $350^{\circ} \mathrm{C}$ to $500^{\circ} \mathrm{C}$, demonstrating that temperature variations cause extensive damage of the material. However, no obvious difference was found between the two isothermal tests analyzed regarding the number of cycles to failure of the specimens, confirming that in this temperature range the material maintains a good cyclic resistance. Hence, designs based solely on the isothermal fatigue of components that work at high temperatures are not reliable, thus requiring a more in-depth study of the behavior of the materials subjected to this phenomenon, including tests at different temperature intervals (anisothermal fatigue) and in a variable range of stresses and strains.

Figure 3 indicates that the longest IF life of specimens occurs within an intermediary range of the applied temperature. In this range, the shortest life found for $316 \mathrm{~L}(\mathrm{~N})$ austenitic 


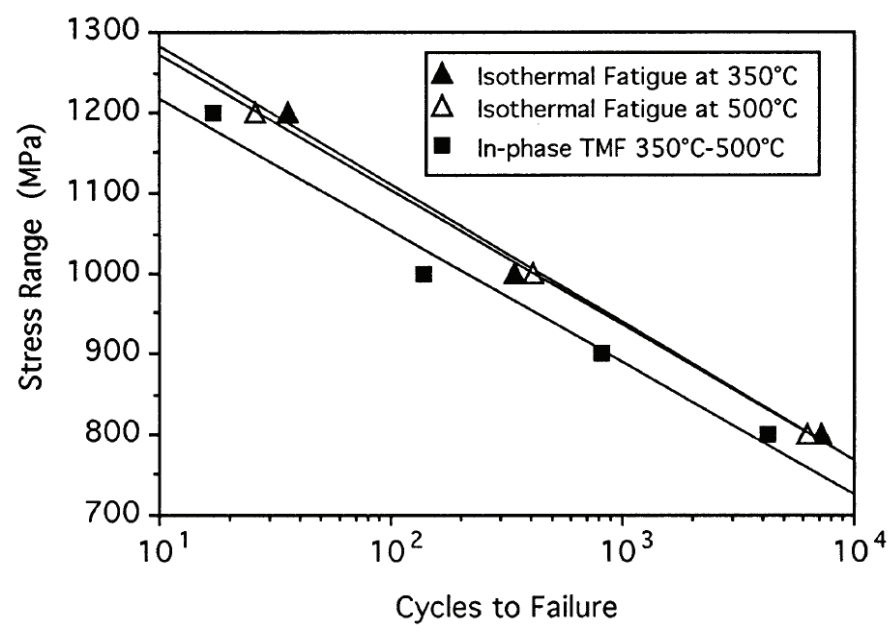

Fig. 2. IF and TMF curves [SHI et al., 1998].

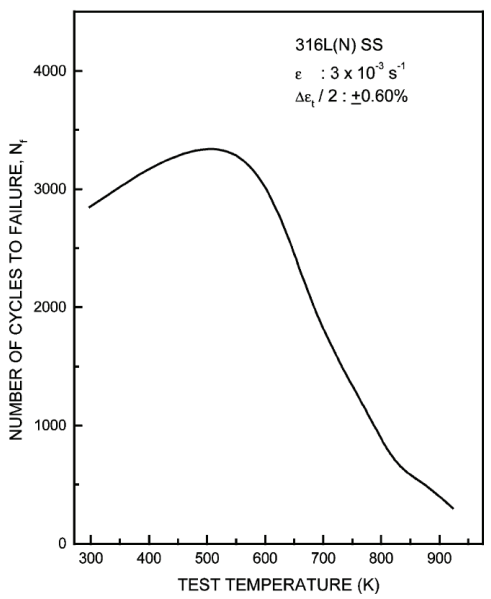

Fig. 3. Influence of temperature on the fatigue life [SRINIVASAN et al., 2003

stainless steel was found at ambient temperature at which the strain induced the formation of martensite phase.

The microstructural recovery of the material, which was responsible for the increased life, occurred at the temperature of $573 \mathrm{~K}\left(300^{\circ} \mathrm{C}\right)$. The reduction of life with continuous increases in temperature is attributed to several effects of dynamic strain, such as the concentration of stresses produced in sites of stacking unconformities when the maximum stress of the cycle is reached, causing an increase in crack growth rate.

This is clearly evident at temperatures above $873 \mathrm{~K}\left(600^{\circ} \mathrm{C}\right)$, at which the lifetime was significantly reduced by oxidation [SRINIVASAN et al., 2003].

Another aspect to be observed under in IF with controlled strain is the behavior of cyclic stress as a function of life. The behavior of the 316L (N) austenitic stainless steel was monitored during four stages, as illustrated in Figure 4 [SRINIVASAN et al., 2003]. 


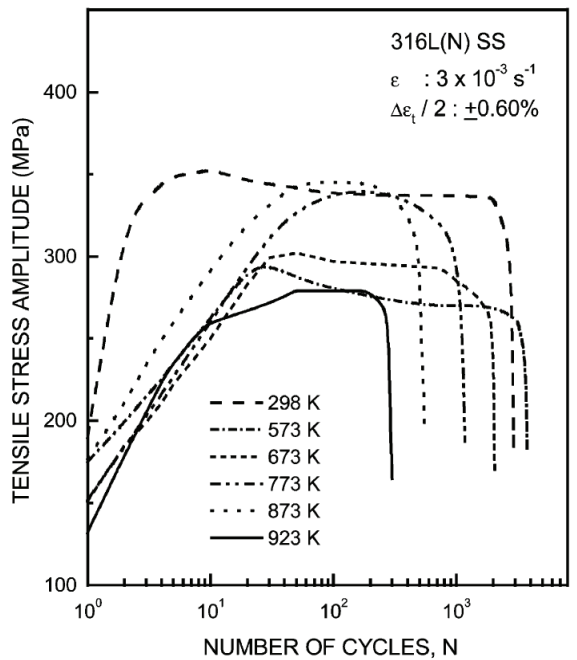

Fig. 4. Cyclic stress response as a function of temperature [SRINIVASAN et al., 2003].

The alloy exhibited a brief period of cyclic hardening, reaching its maximum stress in the early stage of life, followed by cyclic softening before attaining the stable regime. In the period prior to fracture, the stress amplitude decreased rapidly, indicating crack nucleation and propagation.

This figure also shows that the amplitude of the peak stress increased with rising temperature from 573 to $873 \mathrm{~K}$, and also that some factors contribute to the drop in the material's strength with the increase in temperature. These factors are an abnormal cyclic hardening rate and reduction of the amplitude of plastic strain in the lifetime intermediary to fracture, and an increase in the maximum stress rate in the initial cycles in response to increased temperature, which develop due to the inductive interaction between diffusion solutes and mobility of the unconformities during strain. All these phenomena are considered manifestation processes of the period of dynamic strain.

\section{Materials and methods}

Table 1 lists the chemical composition of the four gray cast iron alloys that are used in the production of automotive brake discs and that were the object of this study.

After selecting these four alloys, isothermal and thermomechanical fatigue tests were performed on specimens in conditions of strain, in-phase and out-of-phase. The failure criterion adopted was a 50\% decrease of the maximum load reached during the test. .

Figure 5 (a) shows a Y-shaped block, according to the ASTM A476/476M standard, indicating regions $A$ and $B$ from which the test specimens were removed. Figure 5 (b) shows the dimensions and geometry of the test specimens used in the IF and TMF tests.

Samples were removed from regions $\mathrm{A}$ and $\mathrm{B}$ of the $\mathrm{Y}$-shaped blocks to machine fabricate the specimens for the TMF and IF tests, as indicated in Figure $\mathbf{5 b}$.

TMF and IF tests were performed in the Laboratory of Mechanical Properties of the Department of Materials, Aeronautics and Automotive Engineering at the Engineering School of São Carlos, University of São Paulo. All tests were conducted in a $250 \mathrm{kN}$ capacity 


\begin{tabular}{|c|c|c|c|c|}
\hline \multirow{2}{*}{ Elements } & \multicolumn{4}{|c|}{ Alloys } \\
\cline { 2 - 5 } & $\mathbf{A}$ & $\mathbf{B}$ & $\mathbf{C}$ & $\mathbf{D}$ \\
\hline \%C & 3.36 & 3.45 & 3.71 & 3.49 \\
\hline \%Si & 2.07 & 2.11 & 2.0 & 1.87 \\
\hline \%Mn & 0.63 & 0.71 & 0.69 & 0.53 \\
\hline \%P & 0.03 & 0.068 & 0.059 & 0.03 \\
\hline \%S & 0.06 & 0.05 & 0.052 & 0.11 \\
\hline \%Cr & 0.16 & 0.30 & 0.19 & 0.29 \\
\hline \%Mo & 0.06 & 0.41 & 0.42 & - \\
\hline \%Cu & 0.08 & 0.10 & 0.40 & 0.52 \\
\hline
\end{tabular}

Table 1. Cast iron alloys chemical composition (weight \%)
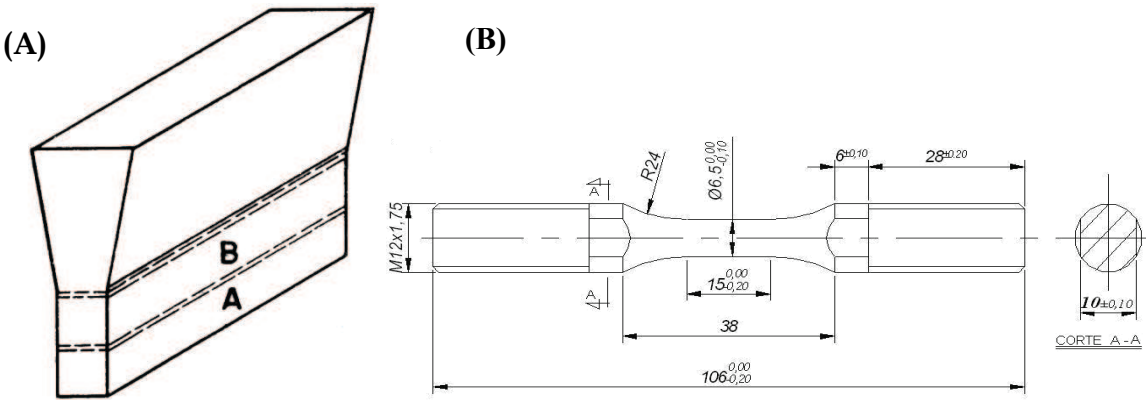

Fig. 5. (A) Y-shaped block according to the ASTM A476/476M standard, showing regions A and $B$ from which the specimens were removed, and (B) geometry and dimensions of specimen used in the TMF and IF tests, dimensions in $\mathrm{mm}$.

MTS 810 servo-hydraulic testing system, equipped with an MTS Micro Console 458.20 controller, Figure 6 and specially adapted to for TMF tests under total strain control. A high temperature axial strain gauge, MTS model 632.54F-14, was used to control the amplitude of total strain. The hydraulic grip system was an MTS model $680.01 \mathrm{~B}$, which is suitable for mechanical tests at high temperatures.

The test specimens were heated in a $75 \mathrm{~kW}$ inductive heating system operating at a frequency of $200 \mathrm{kHz}$. The temperature was measured using an optical pyrometer equipped with a laser target focused midway along the length of the specimen, providing the input for the temperature controller, which received the command signal from a microcomputer. The temperature gradient along the specimen length was minimized using an induction coil with optimized geometric dimensions. The auxiliary cooling system of the clamps grips for the thermomechanical fatigue tests consisted of two spiral copper tubes for circulating cold water and two compressed air pipes attached at to the upper and lower ends of the clamps grips. Figure 7 shows a localized detailed view of the region where the test specimen was fixed in the MTS 810 machine. 


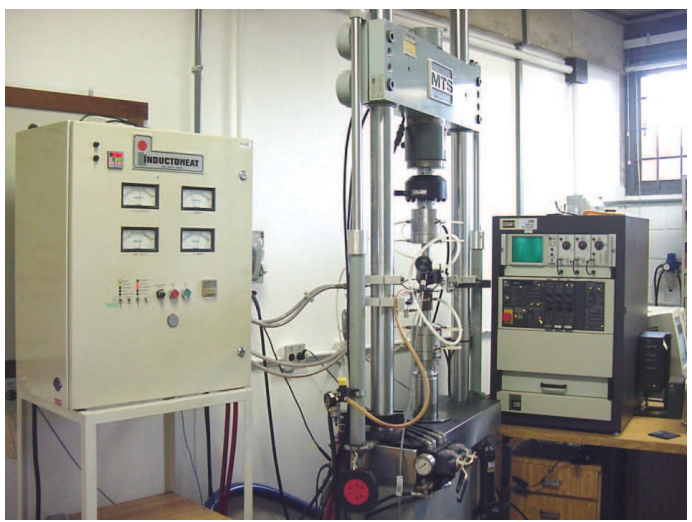

Fig. 6. Overall view of the testing apparatus, showing the induction furnace and the MTS 810 servo-hydraulic testing system.

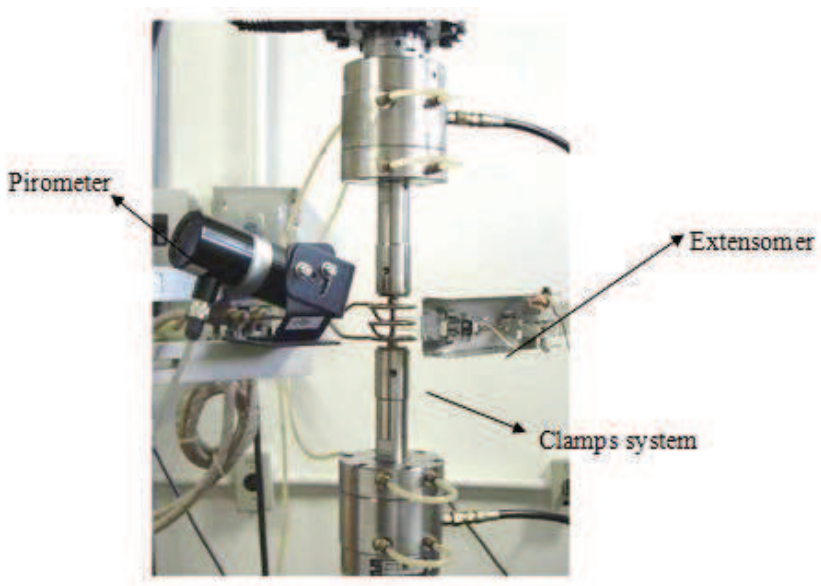

Fig. 7. Detail of the specimen, induction coil, auxiliary cooling system of the grips, and the strain gauge with ceramic rods used in the tests.

The TMF tests were performed in thermal cycles of $120 \mathrm{~s}$, the minimum time required to allow for stable cooling of the gray cast iron specimen and to maintain synchronism between the thermal and mechanical cycles, load ratio, $R=-1$, as illustrated in Figures 8 (a) and (b).

In-phase and out-of-phase TMF tests were carried out in the temperatures from 300 to $600^{\circ} \mathrm{C}$. For in-phase TMF, positive strain corresponds to the maximum temperature of the cycle, negative strain corresponds to the minimum temperature of the cycle, and strain is equals zero at the temperature of $450^{\circ} \mathrm{C}$, as illustrated in Figure 9. 


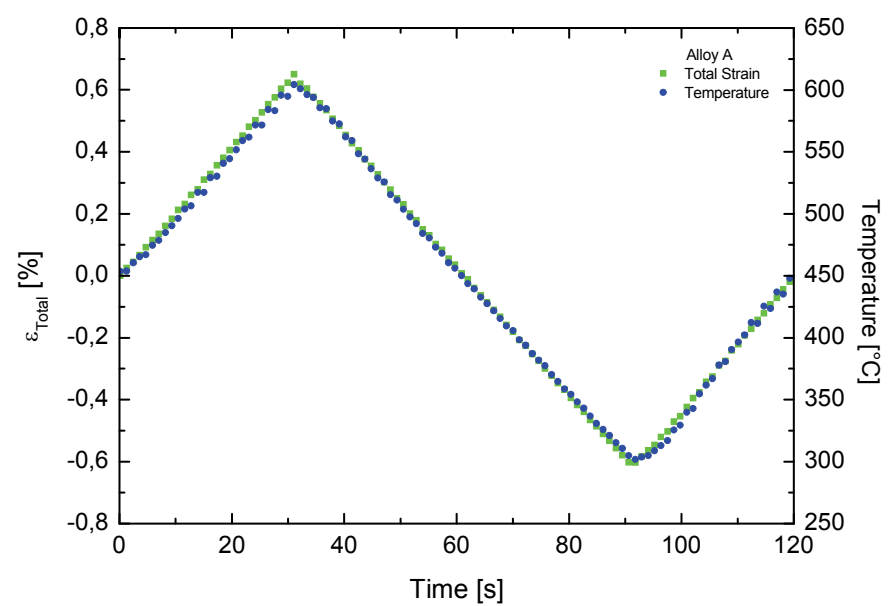

(A)

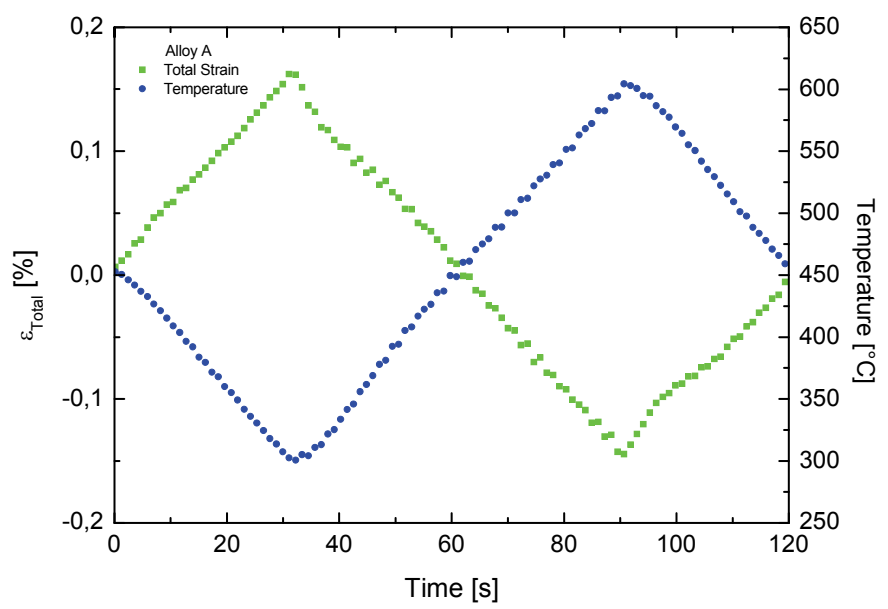

(B)

Fig. 8. Variation of total strain as a function of time and temperature, in initial cycles of TMF tests on alloy A, under controlled mechanical strain (0.4\%): (A) in-phase, and (B) out-ofphase. 


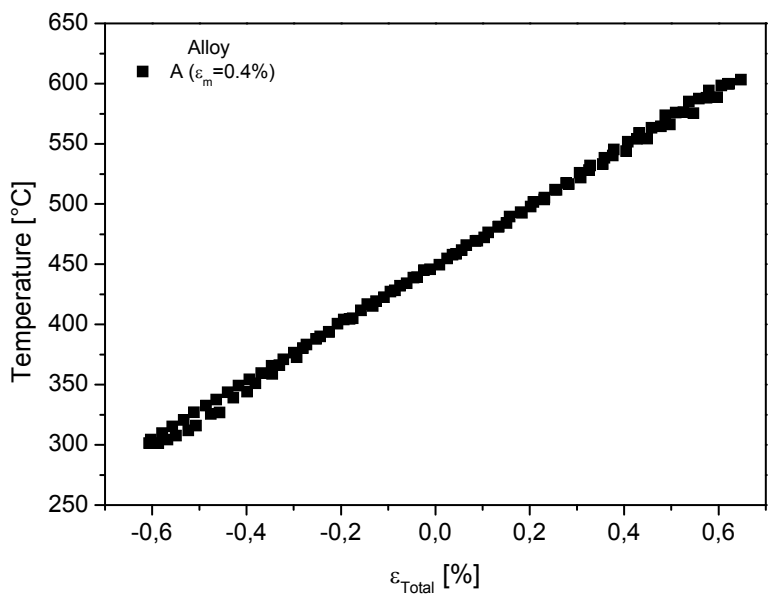

Fig. 9. Temperature hysteresis loop as a function of total strain in an in-phase TMF test. Hysteresis loop for alloy A.

In out-of-phase TMF tests, the positive strain corresponds to the lower cycle temperature, negative strain to the higher cycle temperature, and strain is zero at $450^{\circ} \mathrm{C}$, as indicated in Figure 10.

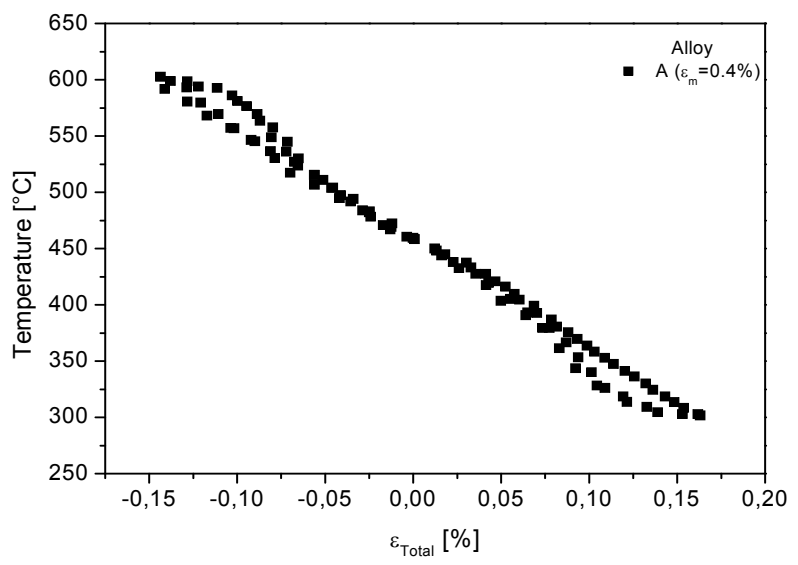

Fig. 10. Temperature hysteresis loop as a function of total strain in an out-of-phase TMF test.

\section{Results and discussion}

The behavior of total strain amplitude $\left(\Delta \varepsilon_{\mathrm{m}} / 2\right)$ as a function of the number of cycles to failure was obtained in alloys A, B, C and D for several levels of strain in the thermal cycle from 300 and $600^{\circ} \mathrm{C}$. It was found that the higher the total strain applied the shorter the lifetime of the material, which is due to the increase in stress required to reach higher strains. 
Figure 11 presents the curve of total strain amplitude, $\Delta \varepsilon_{t} / 2$, vs. the number of reversals to failure $\left(2 \mathrm{~N}_{\mathrm{f}}\right)$, indicating the behavior of the four alloys tested in-phase. As can be seen, at mechanical strain amplitude of $0.10 \%$ in the in-phase test condition, the alloys exhibited an anomalous behavior, i.e., they presented premature fatigue life values than those obtained in the tests at higher amplitudes of mechanical strain. This was very likely due to the occurrence of the phase transformation known as graphite expansion caused by decomposition of the cementite phase in the perlite microconstituent, which transforms into ferrite and vein graphite [ASM International handbook, 1999].

This microstructural transformation leads to a significant decrease in the alloy's mechanical strain amplitude values, producing a rapid drop in the applied tensile load as a function of the number of reversals to failure. This demonstrates the non-validation of the fatigue life criterion adopted in the condition of $50 \%$ decrease of the ultimate load, to study the mechanical behavior of gray cast iron loaded under thermomechanical fatigue at very low levels of mechanical strain amplitude.

Thus, since the results for the strain amplitude of $0.1 \%$ are not valid, they were disregarded in the construction of the tendency lines in Figure 11.

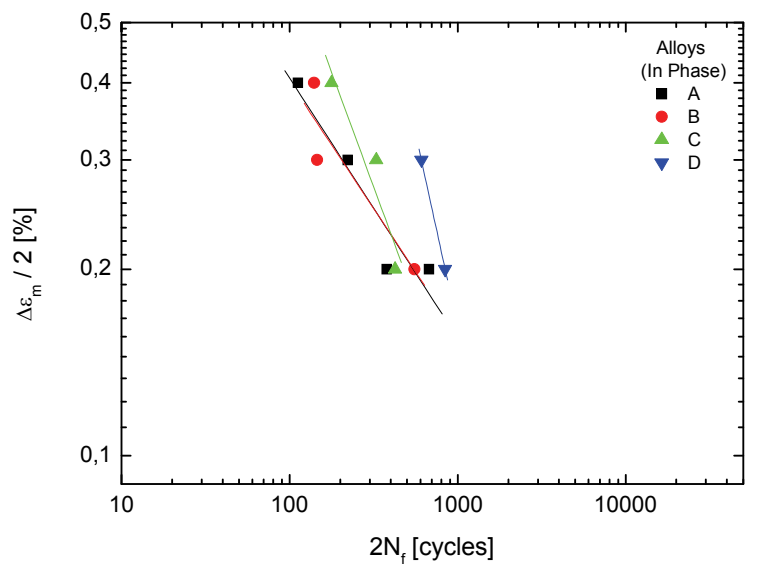

Fig. 11. Comparative plot of the mechanical strain amplitude of the four alloys as a function of the number of reversals to failure in the TMS in-phase condition.

The results obtained in the in-phase loading condition indicate that the behavior of the gray cast iron alloys A, B, and C in in-phase TMF were very similar or superior in terms of the number of reversals to failure at mechanical strain amplitudes of $0.2 \%, 0.3 \%$ and $0.4 \%$. In other words, the three alloys presented practically the same in-phase life at values of mechanical strain amplitude equal to or higher than $0.2 \%$.

As the graph in Figure $\mathbf{1 1}$ indicates, alloy $\mathbf{D}$ presented the best performance in in-phase TMF at all of the applied strain amplitudes. It was thus demonstrated that, among the four gray cast iron under study, the alloy with the best performance was the one with relatively low equivalent carbon content and containing the alloying elements chromium and copper. These conclusions were based on the results of in-phase TMF, where alloy $\mathbf{A}$, albeit devoid of any special alloying element, presented a behavior similar to that of both alloys $\mathbf{C}$ and $\mathbf{B}$, which are the most alloyed. 
Figure 12 depicts the behavior of the four alloys in thermomechanical out-of-phase fatigue. Note that in this loading condition, the alloying elements as well as the equivalent carbon content exerted little or no influence on the low-cycle fatigue strength of the alloys.

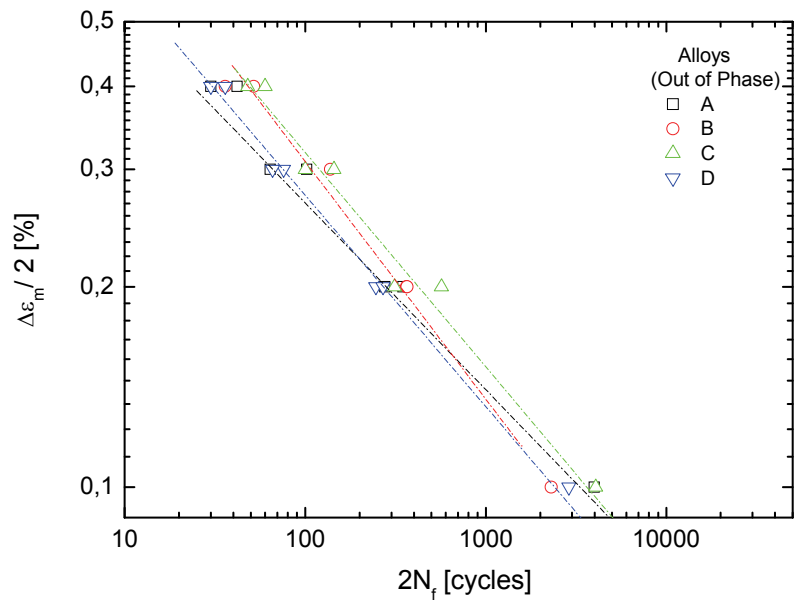

Fig. 12. Comparative plot of the mechanical strain amplitude $v$ s. number of reversals to failure of the four alloys, in TMF out-of-phase.

To facilitate a comparison of the results of the alloys' behavior in both TMF conditions, they were plotted in the same figure, but without taking into account the mechanical strain amplitudes less than $0.2 \%$. This artifice allowed for a clearer view of the performance of the alloys (Figure 13).

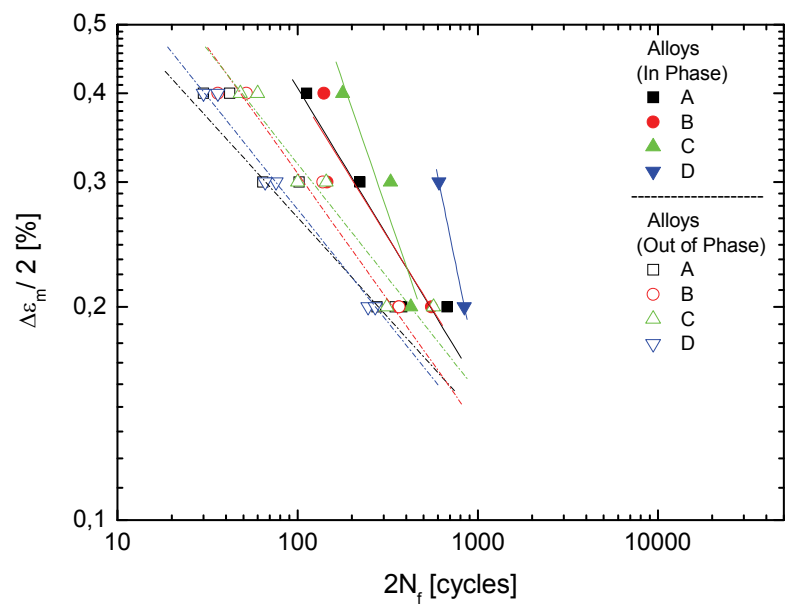

Fig. 13. Comparative plot of the mechanical strain amplitude vs. number of reversals to failure of the four alloys, in-phase and out-of-phase, neglecting amplitudes lower than $0.2 \%$. 
Based on the curves in Figure 13, it can be stated that among the low-cycle TMF tests carried out on specimens of four gray cast iron alloys, the ones performed in the out-of-phase condition were the most critical, since they led to failure in a lower number of reversals. This greater severity of the out-of-phase tests is justified by the fact that the tensile stresses in this test condition are applied at the lowest temperatures of the cycle, in which the material presents low ductility, thus requiring the application of higher stresses to become strained than those that would be required to strain it at higher temperatures. The same reasoning with respect to temperature can be employed to study the behavior of compressive stresses. The effect of the test condition on the application of stresses is easily observed from the behavior of the mean stress curves in the low-cycle thermomechanical fatigue tests. These curves were negative in the in-phase and positive in the out-of-phase condition, as displayed in Figure 14.

The total strain amplitude that occurs in a TMF test is the sum of the mechanical strain amplitude, which is predetermined, and the amplitude of thermal strain, which is a function of the coefficient of thermal expansion of the material and the variation in temperature.

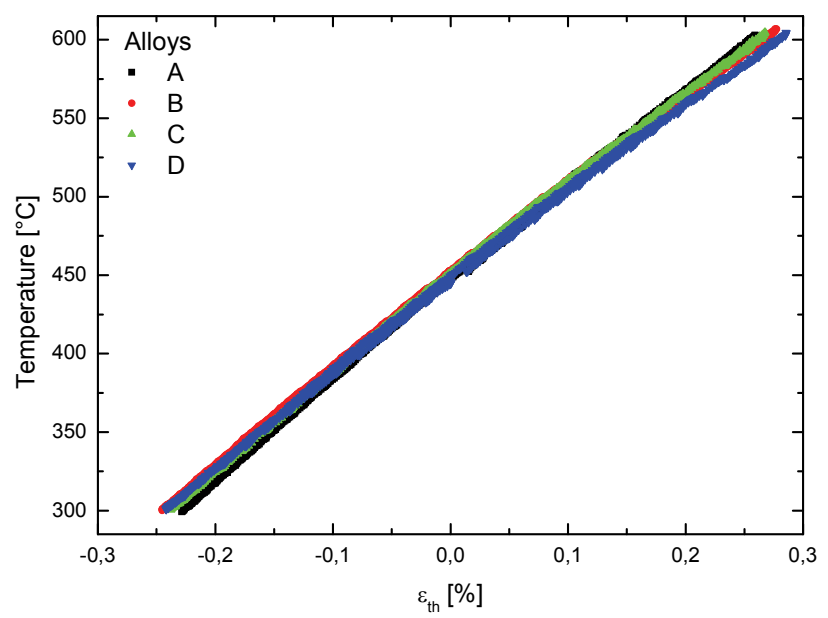

Fig. 14. Thermal strain presented by alloys A, B, C and D in response to temperature increase.

Therefore, the value of the percent amplitude of thermal strain employed to obtain the percent of mechanical strain amplitude for the four alloys of this study in the thermomechanical fatigue tests was $0.3 \%$.

In order to ascertain whether the IF tests could be adopted, as is normally done, to predict the alloys' behavior in TMF, the IF and TMF curves of the four alloys of this study were plotted on the same graphs of \% of total strain amplitude as a function of the number of reversals. As can be seen in the plots in Figures 15, 16, 17 and 18, when subjected to IF at any of the temperatures of $25^{\circ} \mathrm{C}, 300^{\circ} \mathrm{C}$ and $600^{\circ} \mathrm{C}$, alloys $\mathbf{A}, \mathbf{B}, \mathbf{C}$ and D presented longer lifetimes than in out-of-phase TMF, indicating an increase in the severity of the test when temperature variations occur during cyclic loading. 


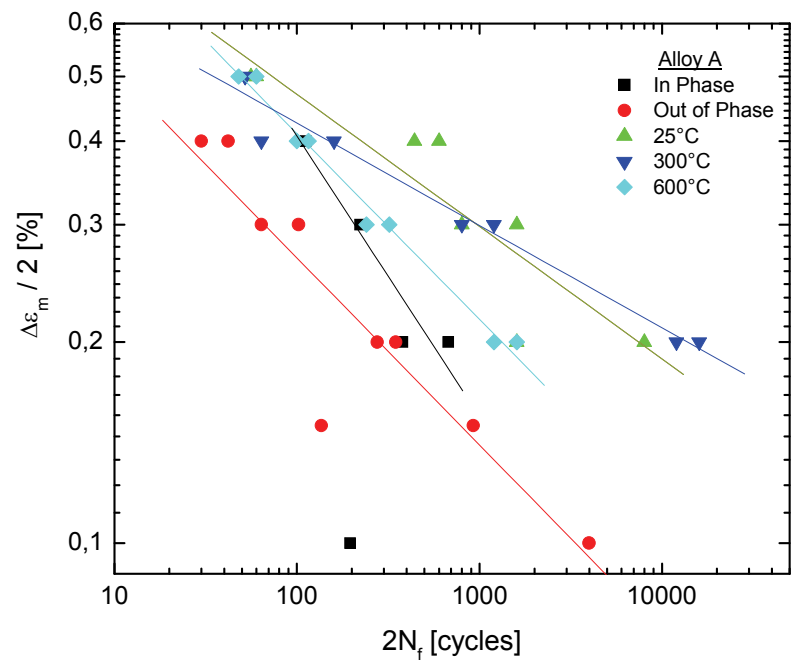

Fig. 15. Mechanical strain amplitude as a function of number of reversals to failure for alloy A. Comparison of in-phase and out-of-phase TMF, and IF at $25^{\circ} \mathrm{C}, 300^{\circ} \mathrm{C}$ and $600^{\circ} \mathrm{C}$.

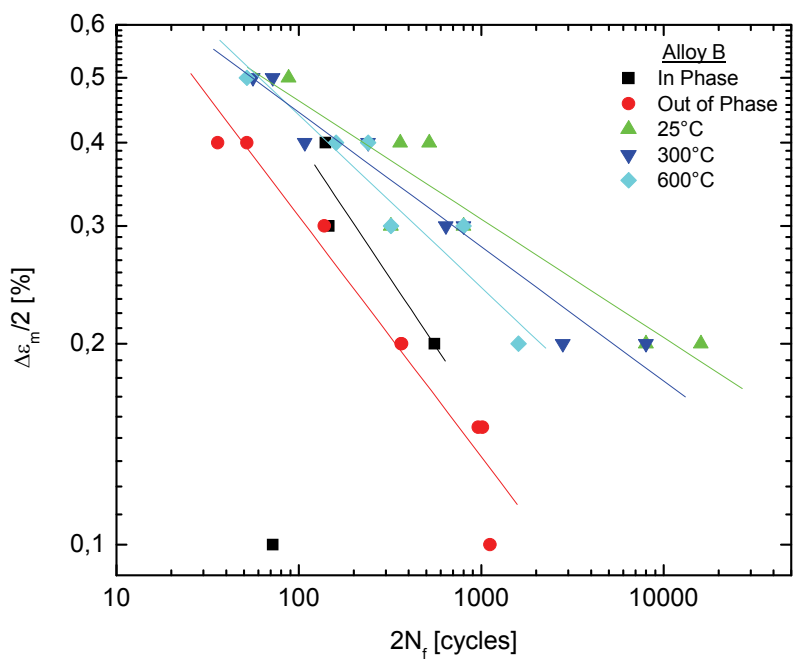

Fig. 16. Mechanical strain amplitude as a function of number of reversals to failure for alloy B. Comparison of in-phase and out-of-phase TMF, and IF at $25^{\circ} \mathrm{C}, 300^{\circ} \mathrm{C}$ and $600^{\circ} \mathrm{C}$ 


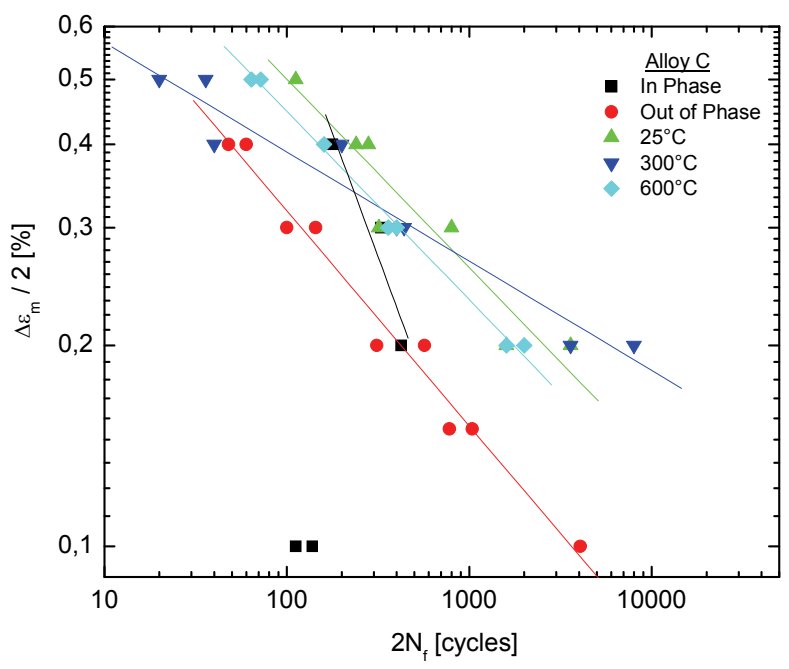

Fig. 17. Mechanical strain amplitude as a function of number of reversals to failure for alloy C. Comparison of in-phase and out-of-phase TMF, and IF at $25^{\circ} \mathrm{C}, 300^{\circ} \mathrm{C}$ and $600^{\circ} \mathrm{C}$.

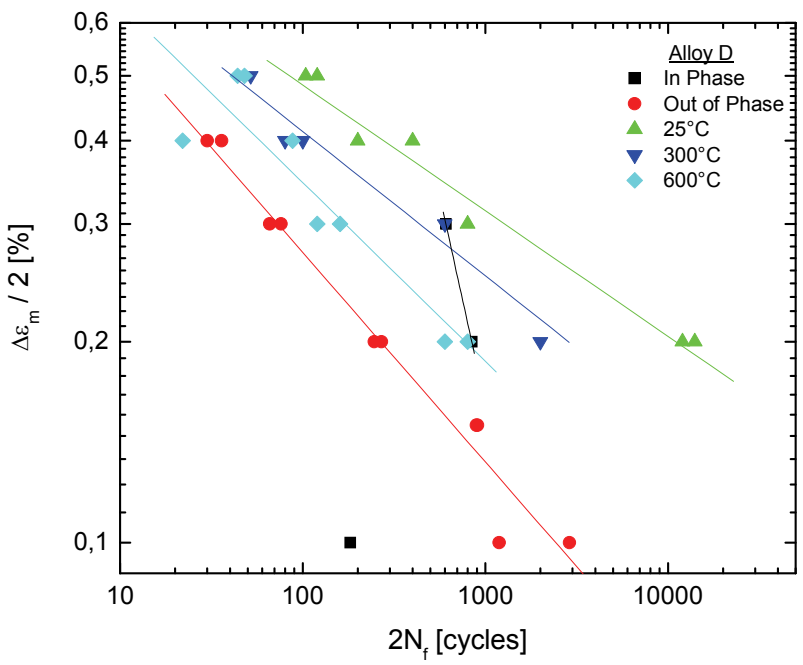

Fig. 18. Mechanical strain amplitude as a function of number of reversals to failure for alloy D. Comparison of in-phase and out-of-phase TMF, and IF at $25^{\circ} \mathrm{C}, 300^{\circ} \mathrm{C}$ and $600^{\circ} \mathrm{C}$. 
As can be seen from the curves, the severity of the tests increases, and hence, the lifetime decreases in the following sequence: IF at $25^{\circ} \mathrm{C}$, IF at $300^{\circ} \mathrm{C}$, IF at $600^{\circ} \mathrm{C}$ and out-of-phase TMF. This clearly indicates that IF tests are unsuitable to predict thermomechanical fatigue behavior, at least in the case of the materials of this study.

The precision of the direction to be considered for the in-phase TMF curves, particularly for alloy $\mathbf{D}$, was impaired because the results of the mechanical strain amplitude of $0.1 \%$, due to the anomalous results, were not considered. Thus, they were not analyzed from the standpoint of severity. In general, and apart from anomalies, the smaller the preestablished mechanical strain the longer the duration of thermomechanical fatigue tests; hence, phenomena such as creep and oxidation have an opportunity to act, reducing the material's lifetime.

The gray cast iron alloys that are used in the production of automotive brake discs were subjected to IF tests because vein graphite behaves like microcracks. Therefore, the conventional method of calculating the plastic and elastic components of strain cannot be used because it would yield incorrect values since, depending on the hysteresis, the tensile unloading tangent could find negative values of plastic strain. Therefore, the extent of hysteresis at half-life was determined by the mean stress, as shown in Figure 19 [KANDIL, 1999].

Note that the distance $\mathbf{d b}$ corresponds to the plastic strain amplitude, the horizontal distance ac corresponds to the total strain amplitude, and the vertical distance ac corresponds to the stress amplitude; $\mathbf{E}_{\mathbf{1}}$ is the modulus of elasticity in tensile unloading, and $\mathbf{E}_{2}$ is the modulus of elasticity in compressive unloading.

The plots of strain amplitude versus number of reversals $\left(\Delta \boldsymbol{\varepsilon}_{\mathrm{t}} \times \mathbf{2} \mathbf{N}_{\mathrm{f}}\right)$ (Figures 20 to 25) indicate that the lifes of the alloys under study showed significant differences at $25^{\circ} \mathrm{C}, 300^{\circ} \mathrm{C}$ and $600{ }^{\circ} \mathrm{C}$. This occurred at all the levels of strain analyzed, i.e., $0.2 \%, 0.3 \%, 0.4 \%$ and $0.5 \%$, due to the low ductility of the alloys in question. In these cases, the equivalent carbon (CE) does not seem to exert any influence on fatigue life at any of the test temperatures. However, it was found that the life of alloy B increased along with increasing temperature, which is due to the presence of alloying elements such as molybdenum and chromium, indicating that these elements increase the materials' hot mechanical strength.

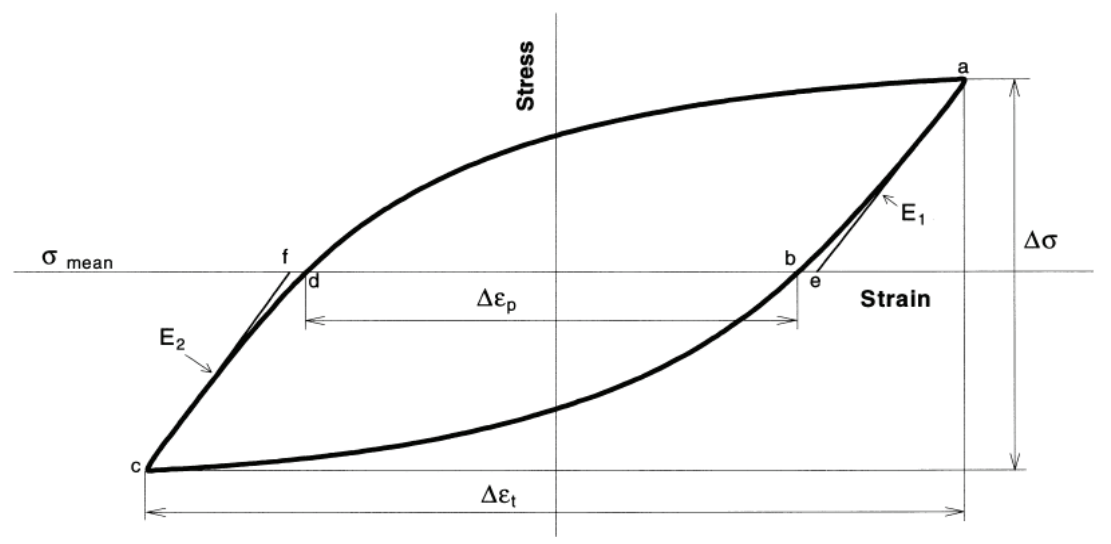

Fig. 19. Hysteresis curve [KANDIL, 1999].

The alloys with high mechanical strength require greater stresses to become strained. Therefore, an analysis of the behavior of the alloys of this study based on the plots of stress 
amplitude vs. number of reversals $\left(\sigma \mathbf{x} 2 \mathbf{N}_{\mathbf{f}}\right)$ at the temperatures of $25^{\circ} \mathrm{C}$ and $300^{\circ} \mathrm{C}$ (Figures 20 to 25 ) indicates that there was no significant decrease in the stress amplitude of the four alloys. However, when the temperature reaches about $600^{\circ} \mathrm{C}$ (Figure 25), there is a more pronounced decline in the stress amplitude of the alloys containing little or no molybdenum, clearly evidencing its relationship with the increase in resistance at high temperatures. This therefore clearly shows that the alloys most resistant to a decrease in their mechanical properties in response to temperature, i.e., alloys $\mathbf{B}, \mathbf{A}$ and $\mathbf{D}$, present a better performance in terms of the IF lifetime.

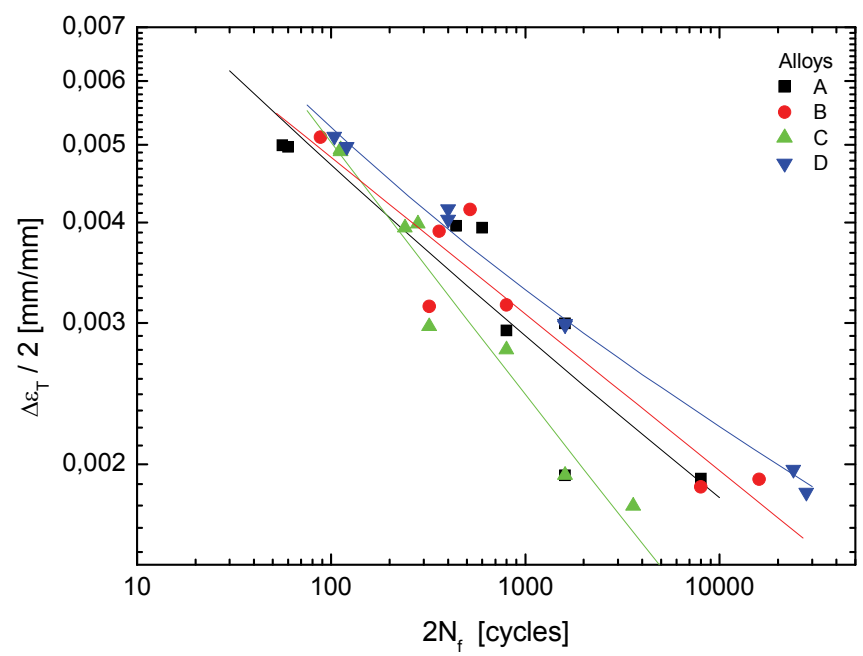

Fig. 20. IF: Comparative plot of total strain amplitude vs. number of reversals at $25^{\circ} \mathrm{C}$.

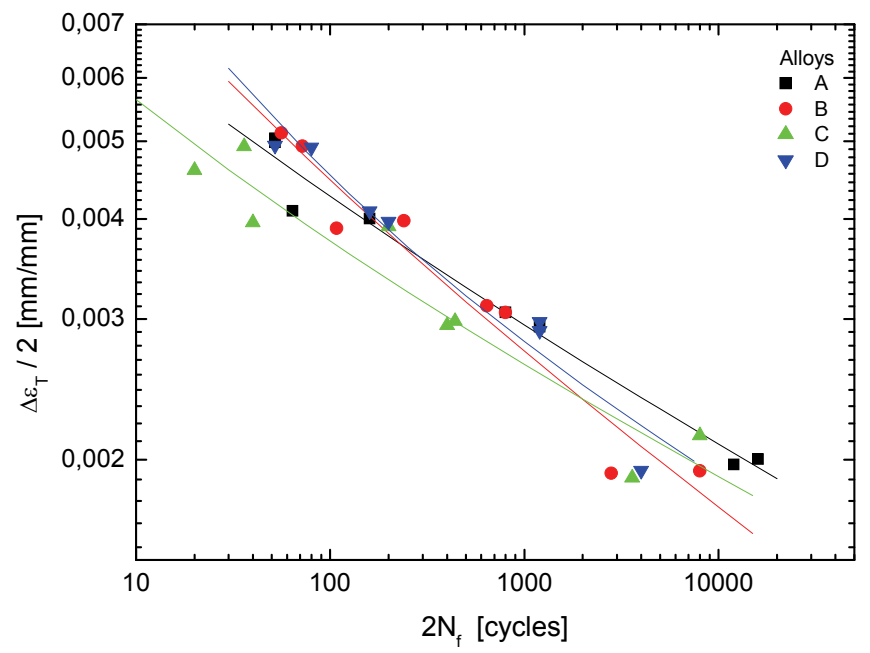

Fig. 21. IF: Comparative plot of total strain amplitude vs. number of reversals at $300^{\circ} \mathrm{C}$. 


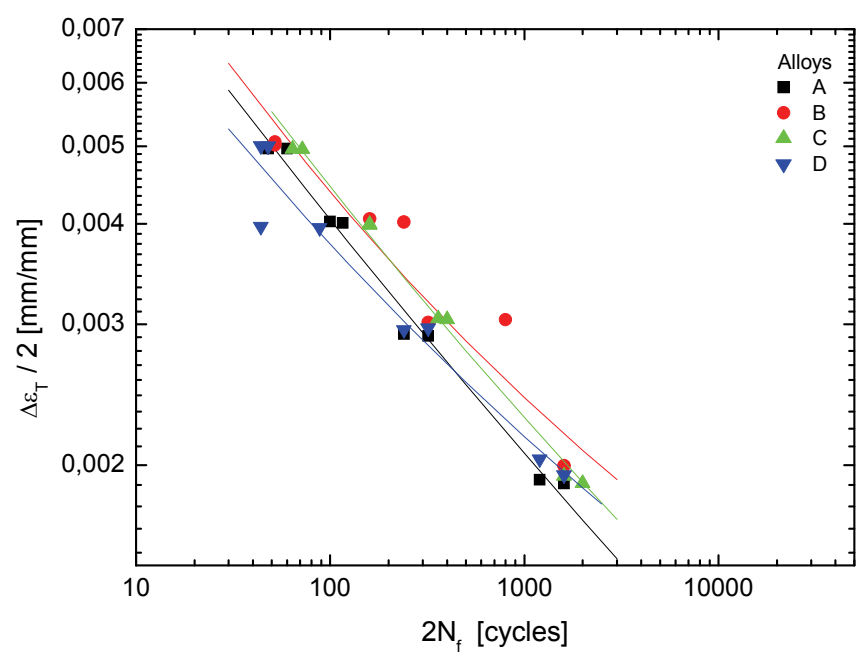

Fig. 22. IF: Comparative plot of total strain amplitude vs. number of reversals at $600^{\circ} \mathrm{C}$.

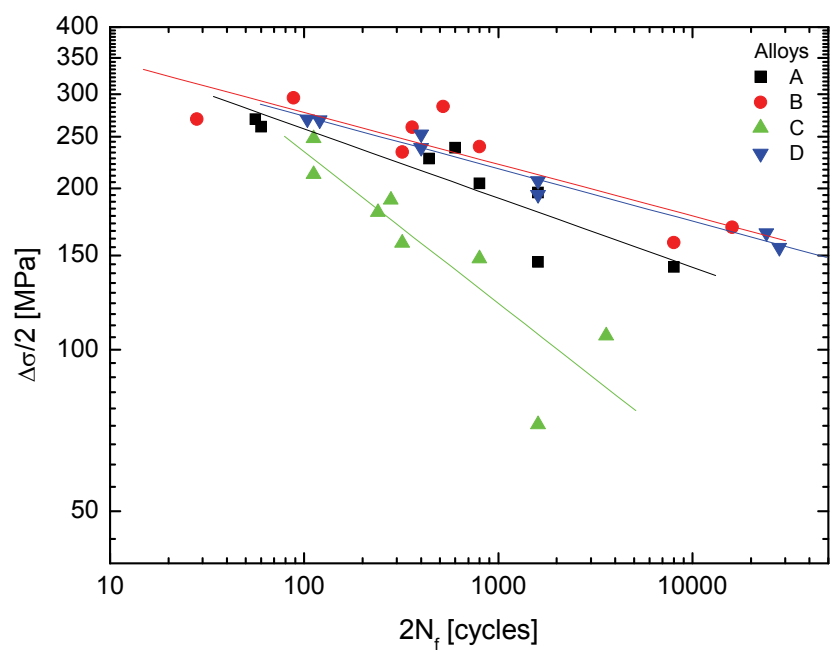

Fig. 23. IF: Comparative plot of stress amplitude vs. number of cycles at $25^{\circ} \mathrm{C}$. 


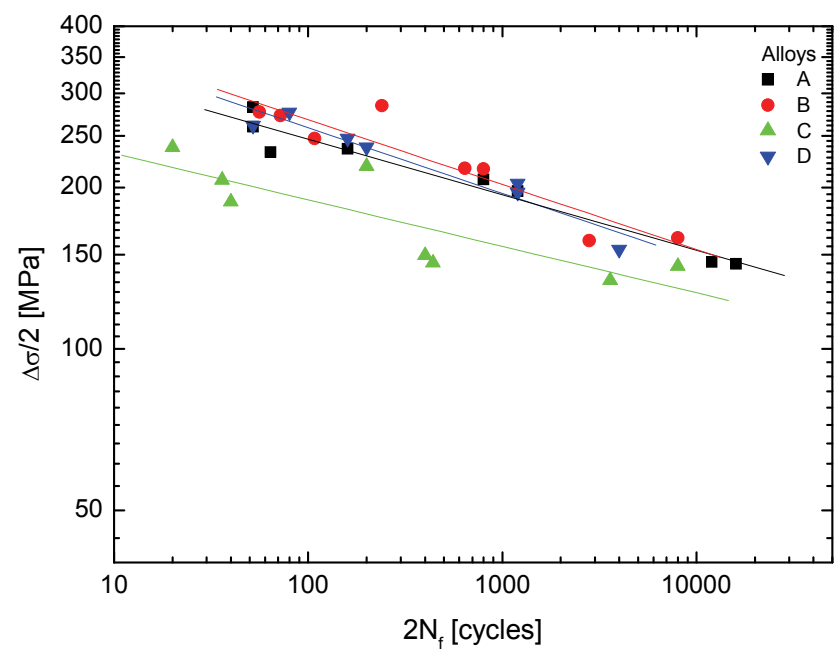

Fig. 24. IF: Comparative plot of stress amplitude vs. number of cycles at $300^{\circ} \mathrm{C}$.

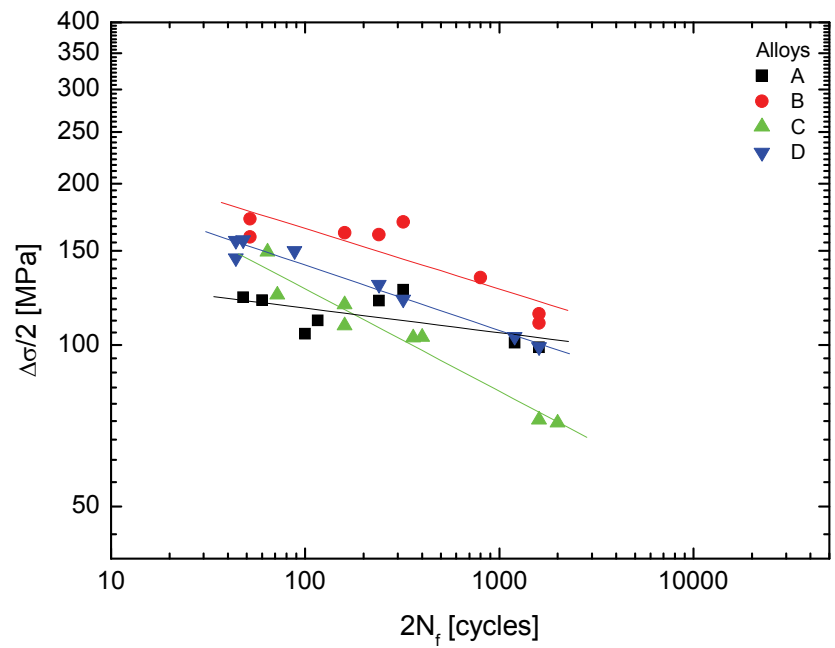

Fig. 25. IF: Comparative plot of stress amplitude vs. number of cycles at $600^{\circ} \mathrm{C}$. 


\section{Conclusions}

- $\quad$ At in-phase TMF mechanical strain amplitudes of $0.10 \%$ the value of fatigue life showed an anomalous behavior in all the analyzed alloys, which failed prematurely according to the adopted criterion of a 50\% decrease in maximum tensile stress. In other words, their $2 \mathrm{~N}_{\mathrm{f}}$ was lower than that of the highest amplitudes of mechanical strain.

- The in-phase TMF curves indicated that the behavior of the gray cast iron alloys A, B and $\mathrm{C}$ were very similar in terms of $2 \mathrm{~N}_{\mathrm{f}}$ at mechanical strain amplitudes of $0.2 \%, 0.3 \%$ and $0.4 \%$. In other words, the three alloys presented practically the same in-phase TMF life at mechanical strains equal to or higher than $0.2 \%$.

- The out-of-phase TMF tests were the most critical, leading specimens to failure in a smaller number of reversals. This greater severity of the out-of-phase tests is explained by the maximum tensile stresses at the lower temperatures of the cycle.

- $\quad$ The best TMF performance was exhibited by the alloys with relatively low equivalent carbon content and containing the alloying elements $\mathrm{Cr}$ and $\mathrm{Cu}$.

- As for the IF properties, the alloys under study did not show a significant difference at temperatures of $25^{\circ} \mathrm{C}, 300^{\circ} \mathrm{C}$ and $600^{\circ} \mathrm{C}$, as indicated by the $\varepsilon-\mathrm{N}$ curves. The $\mathrm{CE}$, was apparently uncorrelated with the fatigue life.

- Based on the $\sigma-\mathrm{N}$ curves one can see that, even at ambient temperature, there is a difference among the alloys. With the increase in temperature there is a decline in the stress amplitude, which is more pronounced in the alloys containing little or no $\mathrm{Cr}$ and Mo. Thus, the alloys with higher mechanical strength require a higher stress to become strained.

- When subjected to IF at any of the temperatures, $25^{\circ} \mathrm{C}, 300^{\circ} \mathrm{C}$ and $600^{\circ} \mathrm{C}$, the alloys presented longer lifes and in out-of-phase TMF, revealed an increase in the severity of the test with the variation in temperature.

- $\quad$ The IF tests were less critical than the out-of-phase TMF tests.

\section{References}

[1] IOMBRILLER, S. F. “Análise térmica e dinânica do Sistema de Freio a Disco de Veículos Comerciais Pesados". Dissertation (doctorate in Mechanical Engineering), São Carlos: USP - Universidade de São Paulo, p. 177, 2002.

[2] MAZUR, Z., LUNA-RAMÍZES, A., JUÁREZ-ISLAS, J. A., CAMPOS-AMEZCUA, A. "Failure Analysis of a Gas Turbine Blade made of Inconel 738 LC Alloy", Engineering Failures Analysis, Elsevier, V. 12, p. 474 - 486, 2005.

[3] Maluf, O. "Fadiga Termomecânica em ligas de ferro fundido cinzento para discos de freios automotivos". PhD. Thesis (doctorate in Science and Materials Engineering), São Carlos: USP - Universidade de São Paulo, p. 47-130, 2007).

[4] BOIOCCHI, T., "Technological Differences between Tractors, Trailers and Impact in the Safety and Drivability", in Colloquium Internacional de Freios, 4, Caxias do Sul, p. 23 - 28, 1999.

[5] WEINTRAUB, M., "Brake additives consultant”, Private Communication, 1998.

[6] HETNARSKI, R. B. "Mechanics and Mathematical Methods - Thermal Stress II", NorthHolland, Oxford, 2nd Series, V. 2, 1991.

[7] SEHITOGLU, H. "Thermal and thermomechanical fatigue of structural alloys". In: ASM HANDBOOK - Fatigue and Fracture. Ohio, V.9, 1996. 
[8] COFFIN Jr., L.F., A study of the effects of cyclic thermal stresses on a ductile metal, Transactions of the ASME, $n^{\circ}$ 53-A76, 1954, p. 931-949.

[9] HETNARSKI, R. B. "Mechanics and Mathematical Methods - Thermal Stress II", NorthHolland, Oxford, 2nd Series, V. 2, 1991.

[10] SHI, H-J., KORN, C., PLUVINAGE, G., "High Temperature Isothermal and Thermomechanical Fatigue on a Molybdenum-Based Alloy", Materials Science and Engineering, A247, p. 180 - 186, 1998.

[11] SRINIVASAN, V.S., VALSAN, M., RAO, B. S., MANNAN, S.L., RAJ, B. “Low Cycle Fatigue and Creep-Fatigue Interaction Behavior of 316L(N) Stainless and Life Prediction by Artificial Neural Network Approach", International Journal of Fatigue, V. 25, p. 1327 1338, 2003.

[12] ASM International handbook. Heat Resistant Materials, pp. 183-186, 1999.

[13] KANDIL, F.A. Cycle Potential ambiguity in the determination of the plastic strain range component in LCF testing. International Journal of Fatigue, 21 (1999), 1013-1018. 


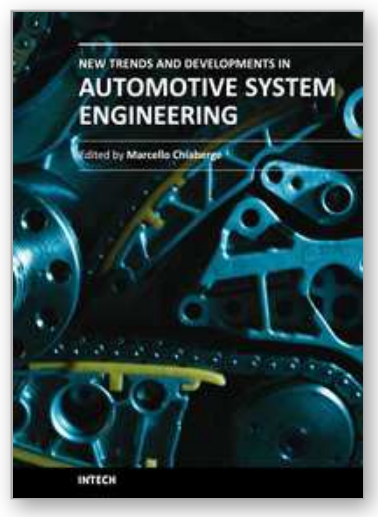

\author{
New Trends and Developments in Automotive System Engineering \\ Edited by Prof. Marcello Chiaberge
}

ISBN 978-953-307-517-4

Hard cover, 664 pages

Publisher InTech

Published online 08, January, 2011

Published in print edition January, 2011

In the last few years the automobile design process is required to become more responsible and responsibly related to environmental needs. Basing the automotive design not only on the appearance, the visual appearance of the vehicle needs to be thought together and deeply integrated with the â€œpowerâ€ developed by the engine. The purpose of this book is to try to present the new technologies development scenario, and not to give any indication about the direction that should be given to the research in this complex and multi-disciplinary challenging field.

\title{
How to reference
}

In order to correctly reference this scholarly work, feel free to copy and paste the following:

Omar Maluf, Jéferson Aparecido Moreto, Maurício Angeloni, Marco Antônio Colósio, José Carlos Santos, Waldek Wladimir Bose Filho and Dirceu Spinelli (2011). Thermomechanical and Isothermal Fatigue Behavior of Gray Cast Iron for Automotive Brake Discs, New Trends and Developments in Automotive System Engineering, Prof. Marcello Chiaberge (Ed.), ISBN: 978-953-307-517-4, InTech, Available from: http://www.intechopen.com/books/new-trends-and-developments-in-automotive-systemengineering/thermomechanical-and-isothermal-fatigue-behavior-of-gray-cast-iron-for-automotive-brake-discs

\section{INTECH}

open science | open minds

\section{InTech Europe}

University Campus STeP Ri

Slavka Krautzeka 83/A

51000 Rijeka, Croatia

Phone: +385 (51) 770447

Fax: +385 (51) 686166

www.intechopen.com

\section{InTech China}

Unit 405, Office Block, Hotel Equatorial Shanghai

No.65, Yan An Road (West), Shanghai, 200040, China

中国上海市延安西路65号上海国际贵都大饭店办公楼 405 单元

Phone: +86-21-62489820

Fax: +86-21-62489821 
(C) 2011 The Author(s). Licensee IntechOpen. This chapter is distributed under the terms of the Creative Commons Attribution-NonCommercialShareAlike-3.0 License, which permits use, distribution and reproduction for non-commercial purposes, provided the original is properly cited and derivative works building on this content are distributed under the same license. 